\title{
Sorption and Desorption of Remazol Yellow by a Fe-Zeolitic Tuff
}

\author{
Marcos José Solache-Ríos, ${ }^{* 1}$ Rafael Villalva-Coyote, ${ }^{1,2}$ and María del Carmen Díaz-Nava ${ }^{2}$
}

${ }^{1}$ Instituto Nacional de Investigaciones Nucleares, Departamento de Química, A. P.18-1027, Col. Escandón, Delegación Miguel Hidalgo, C. P. 11801, México, D. F., México. marcos.solache@inin.gob.mx, Tel.: +52 5553297200x2262; fax: +525553297301 .

${ }^{2}$ Instituto Tecnológico de Toluca, División de Estudios del Posgrado, Av. Tecnológico s/n, Ex Rancho La Virgen, C.P. 52140, Metepec, Estado de México, México.

Received December 8, 2009; Accepted March 29, 2010

\begin{abstract}
The adsorption of remazol yellow from aqueous solution was evaluated using a Fe-zeolitic tuff. The adsorbent was characterized by scanning electron microscopy, IR spectroscopy and X-Ray diffraction. Sorption kinetic and isotherms were determined and the adsorption behavior was analyzed. Kinetic pseudo-second order and Langmuir-Freundlich models were successfully applied to the experimental results, indicating chemisorption on a heterogeneous material. The regeneration of the material was best accomplished by using a $\mathrm{H}_{2} \mathrm{O}_{2}$ solution. The sorption capacity of the Fe-zeolitic tuff increased when the saturated samples were treated with a $\mathrm{H}_{2} \mathrm{O}_{2}$ or $\mathrm{FeCl}_{3}$ solution.
\end{abstract}

Keywords: Remazol, sorption, desorption, Fe-zeolitic tuff.

\section{Introduction}

Color is one of the greatest contaminants in wastewater because it is highly visible and undesirable, causing considerable environmental pollution because of its absorption and reflection of sunlight entering the water; this interferes with the growth of bacteria and impedes the photosynthesis in aquatic plants [1] and also raises the chemical oxygen demand (COD) of the effluents [2]. It has been reported that $2 \%$ of dyes produced annually are discharged in effluent from manufacturing operations while it has been estimated that about $9 \%$ of the total amount (450 000 tons) of dyestuff produced in the world is discharged with textile wastewater [3].

In general, dyestuffs have complex chemical structures which are resistant to biological degradation. There are various methods available for the removal of dyes including membrane-separation, electrochemical, flocculation-coagulation, reverse osmosis, ozone oxidation, biological treatments, sorption, etc. [1]. Adsorption processes, on the other hand can be alternative methods for the removal of low concentrations of dyes, being economically feasible when compared with other methods.

Natural zeolites, usually regarded as low-cost materials are abundant and have been used as adsorbents for water purification [4]. The regeneration of adsorbents is an important issue in sorption processes. Fenton-driven oxidation, for example, has been proposed for regenerating spent organic-loaded carbons $[5,6]$. The regeneration of zeolites is also an important issue in zeolite utilization. Currently, one of the main regeneration techniques is ion exchange for the restoration of the exchange capacity.
Resumen. Se estudió la adsorción de amarillo remazol utilizando una roca zeolítica acondicionada con hierro. El adsorbente se caracterizó por microscopia electrónica de barrido, espectroscopia IR y difracción de rayos-X. Se determinaron la cinética y las isotermas de sorción y el comportamiento fue analizado. Los resultados experimentales se ajustaron a los modelos de cinética de pseudo-segundo orden y LangmuirFreundlich, indicando sorción química sobre un material heterogéneo. La regeneración del material se logró mejor con una solución de $\mathrm{H}_{2} \mathrm{O}_{2}$. La capacidad de sorción del material zeolítico aumentó cuando las muestras se trataron con soluciones de $\mathrm{H}_{2} \mathrm{O}_{2}$ o $\mathrm{FeCl}_{3}$.

Palabras clave: Remazol, sorción, desorción, roca zeolítica.

Both thermal and chemical methods have been employed to regenerate adsorbents saturated with organic compounds [7-9]. During thermal regeneration and wet oxidation organic contaminants are destroyed concomitantly with the regeneration of the adsorbents. In the former method the organics decompose thermally; in wet oxidation, oxidation in aqueous solution and in air via a free radical mechanism occurs [10]. Fenton's reaction has been studied, showing high efficiency in the destruction of most classes of organics in aqueous solutions [11]. This system is based on hydrogen peroxide, a clean oxidizer and a ferrous salt that generates hydroxyl radicals $\mathrm{HO}$, which are very active for oxidizing organic molecules in an aqueous medium $[12,13]$. Fenton's reagent was used to destroy adsorbed organochloro and remazol yellow contaminants on carbonaceous materials and a surfactant modified zeolite [11, 14]. Remazol yellow was removed using Fenton's reagent from a surfactant modified zeolite, but the surfactant was removed together with the dye and the adsorbent could not be regenerated, however, it was observed that the regenerated clinoptilolite-rich tuff had a higher sorption capacity than the original surfactant modified zeolite [14]. Some studies have reported the degradation of phenol in aqueous solutions using Fe-exchanged zeolite. Orange II was removed by using a bentonite clay-based Fe nanocomposite film as Fenton-type catalyst $[15,16]$.

Indigo carmine removal from aqueous solution was evaluated using Fe-zeolitic tuff. Kinetic pseudo-second order and Langmuir-Freundlich models were successfully applied to the experimental results; this indicated that there were chemisorptions on heterogeneous materials [17].

Therefore, the aim of this work was twofold: first of all, to determine the efficiency of a Fe-zeolitic tuff for the removal of 
remazol yellow dye and secondly, to explore the possibility of regenerating the material using different processes.

\section{Results and Discussion}

\section{Scanning electron microscopy}

Figures 1-4 shows the morphology of the natural zeolitic tuff, sodium and iron modified zeolitic tuffs and the iron zeolitic tuff saturated with remazol yellow, respectively. The typical morphology coffin and cubic-like crystals [18] were best observed in the modified materials. Trgo et al. [19] have shown that the amphoteric nature of hydroxyl surface groups $[=(\mathrm{Al} / \mathrm{Si})-\mathrm{OH}]$ can lead to the formation of sites with such different energies that this mechanical effect increases the number of possible adsorption locations. The chemical compositions of the zeolitic tuff, the sodium and Fe-zeolitic tuff and the saturated Fe-zeolitic tuff with remazol yellow are presented in Table 1 . The main elements, $\mathrm{Si}, \mathrm{Al}$ and $\mathrm{O}$, corresponding to aluminosilicates, were identified. Iron was found in the natural zeolitic tuff being identified by X-Ray diffraction as $\mathrm{Fe}_{2} \mathrm{O}_{3}$. The $\mathrm{Na}$ content diminished when the material was treated with $\mathrm{FeCl}_{3}$ solution; this behavior indicated that sodium was replaced in the material by iron, since the content of this element was higher in the Fe-zeolitic tuff than in the sodium-zeolitic tuff and as a result, it might have induced oxidation processes [20]. The external, internal and effective cation exchange capacities have been reported in a previous research [21].

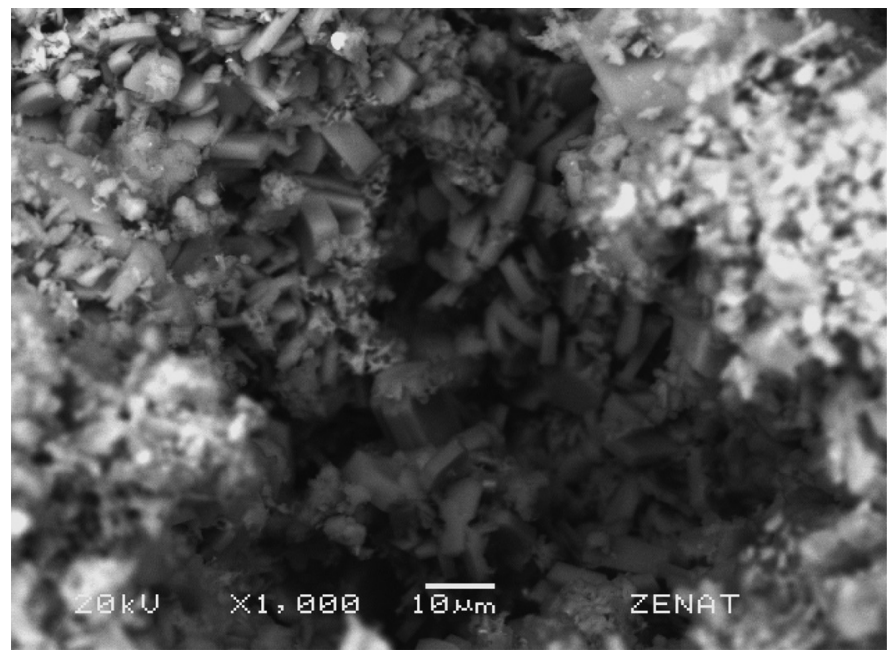

Fig. 1. Scanning electron micrograph of the zeolitic tuff.

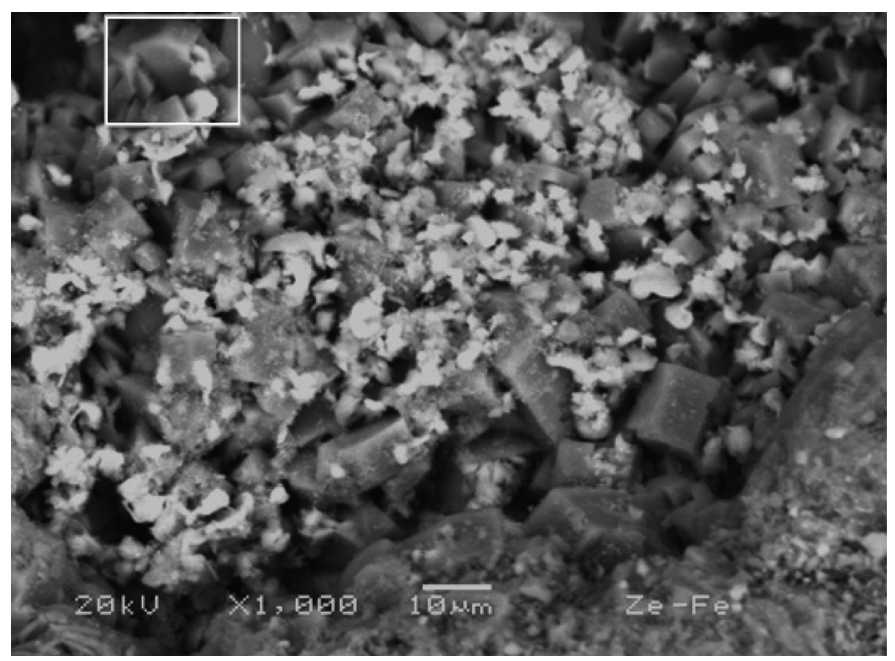

Fig. 3. Scanning electron micrograph of the Fe-zeolitic tuff.

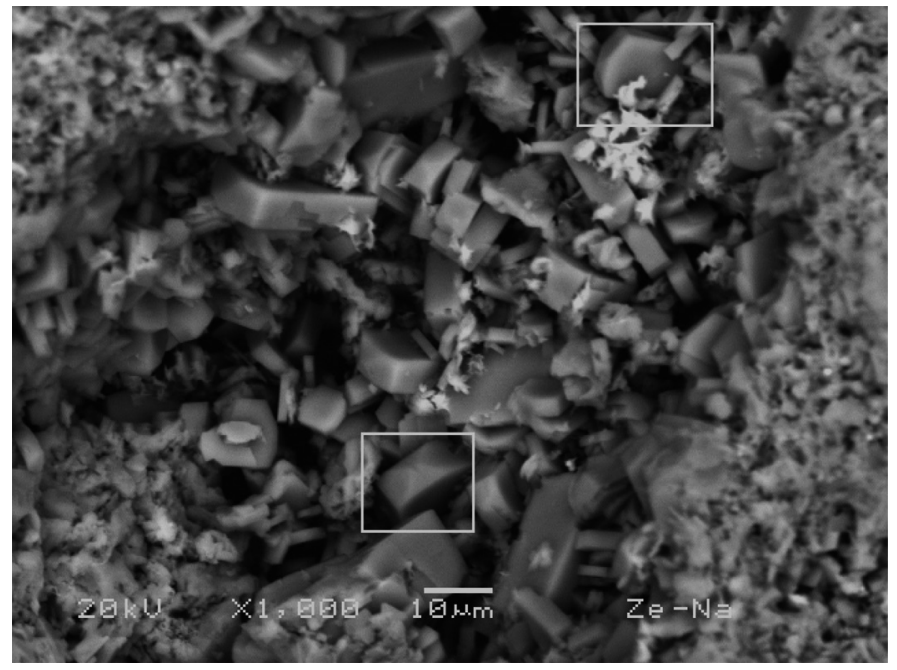

Fig. 2. Scanning electron micrograph of the Na-zeolitic tuff.

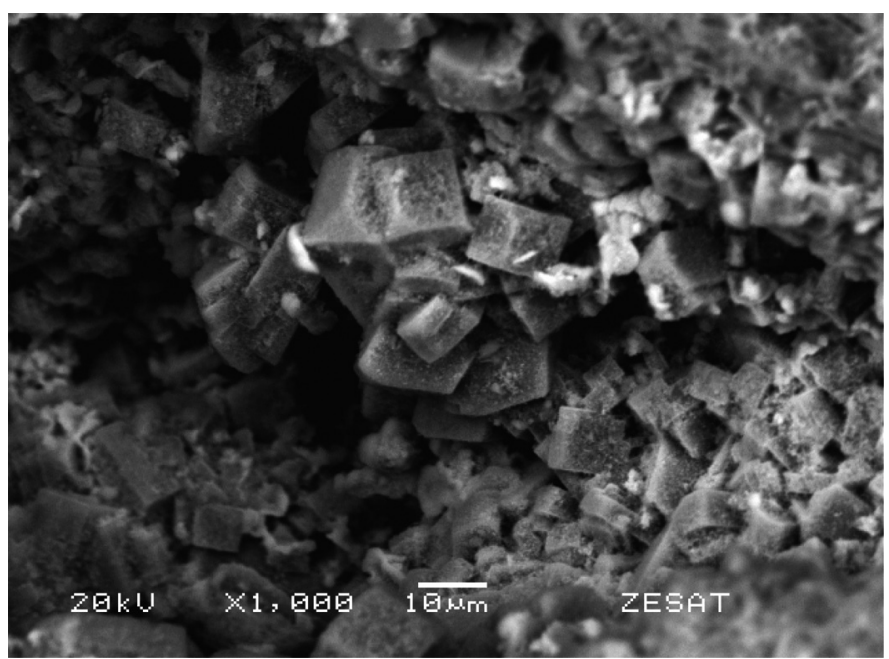

Fig. 4. Scanning electron micrograph of the yellow remazol saturated Fe-zeolitic tuff. 
Table 1. Elemental analysis of the zeolitic tuff, Na-zeolitic tuff, Fe-zeolitic tuff and Fe-zeolitic tuff saturated with remazol yellow.

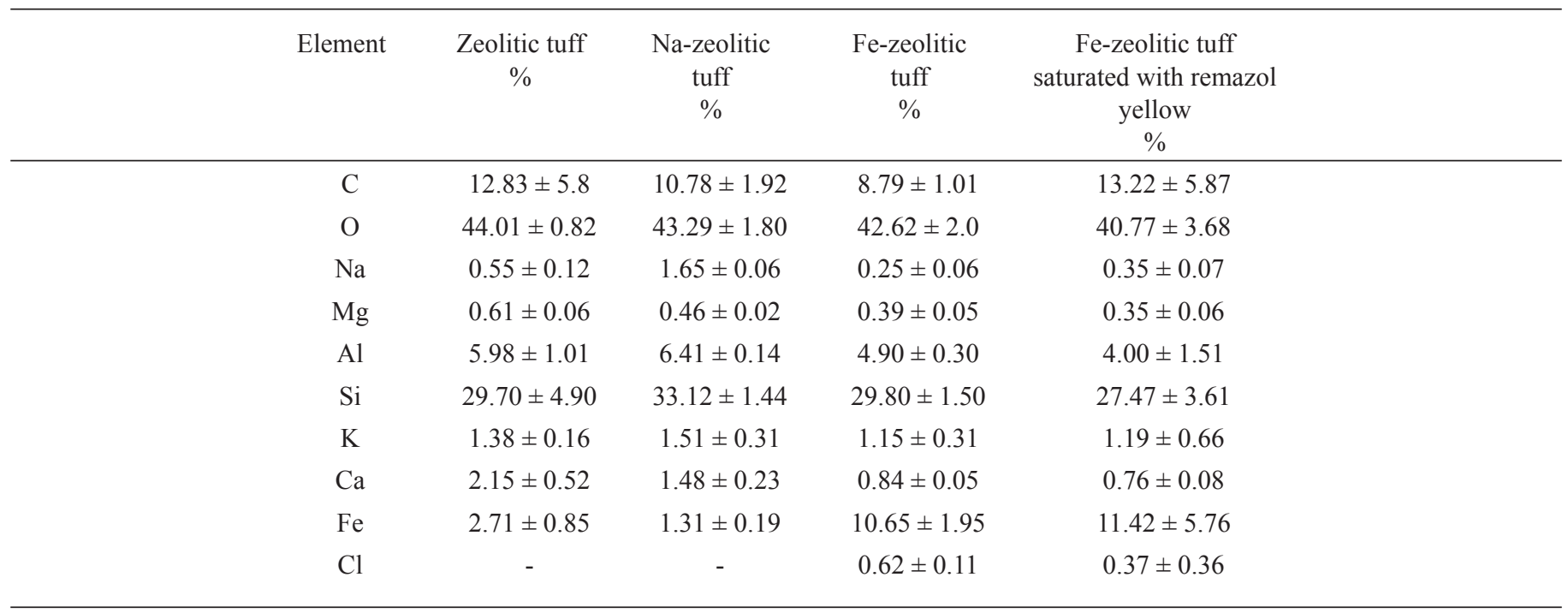

\section{X-ray diffraction (XRD)}

The X-ray powder diffraction patterns of the natural zeolitic tuff, Na-zeolitic tuff, Fe-zeolitic tuff and the Fe-zeolitic tuff saturated with remazol yellow were similar. The diffractograms were compared with clinoptilolite (JCPDS 039-1383) and quartz (JCPDS 33-1161), which were the principal components found in the zeolitic samples; other components found were sodium anortite (JCPDS 20-0528) and $\mathrm{Fe}_{2} \mathrm{O}_{3}$ (JCPDS 391346). No clay minerals were observed. These results suggest there were no notable changes in the structure of clinoptilolite after it was treated with sodium chloride and iron chloride solutions.

\section{Infrared spectra of zeolitic materials}

The natural sodium, iron and the Fe-zeolitic material saturated with remazol yellow showed similar IR spectra, the absorption peaks observed being assigned mainly to asymmetric and symmetric stretching, which are characteristics of this kind of material [22]. The characteristic infrared adsorption, which might be attributed to the pore opening aspect of the structure, was not observed since these frequencies generally occur below $400 \mathrm{~cm}^{-1}$, beyond the region studied [22]. No absorption peaks due to remazol yellow were observed in the material saturated with this dye, probably because of its low concentration in the samples.

\section{Surface Areas, BET $\left(\mathbf{S}_{\mathrm{BET}}\right)$}

The BET specific surface areas were 6.6, 5.2, 34.5, and 36.5 $\mathrm{m}^{2} / \mathrm{g}$ for the natural zeolitic tuff, the Na-zeolitic tuff, Fe-zeolitic tuff and the dye saturated Fe-zeolitic tuff respectively.
As was observed, the specific surface area increased when the material was treated with $\mathrm{FeCl}_{3}$ solutions. A similar behavior was reported for a zeolitic material treated with a nitrate solution [20]. This behavior could be attributed to pore openings during modifications of the zeolitic tuff.

\section{Sorption kinetics}

Sorption kinetics, expressed in terms of the rate of solute uptake (which governs the residence time), is one of the important considerations for economical wastewater treatment applications [23]. Figure 5 shows the relationship between contact time and the sorption capacities of the sorbent. According to figure 5 , equilibrium was not completely reached even after 168 hours of contact time. One of the problems encountered was that the $\mathrm{pH}$ decreased in the solutions as contact time increased: the initial $\mathrm{pH}$ was 6.5 and after 168 hours it was 3.3;

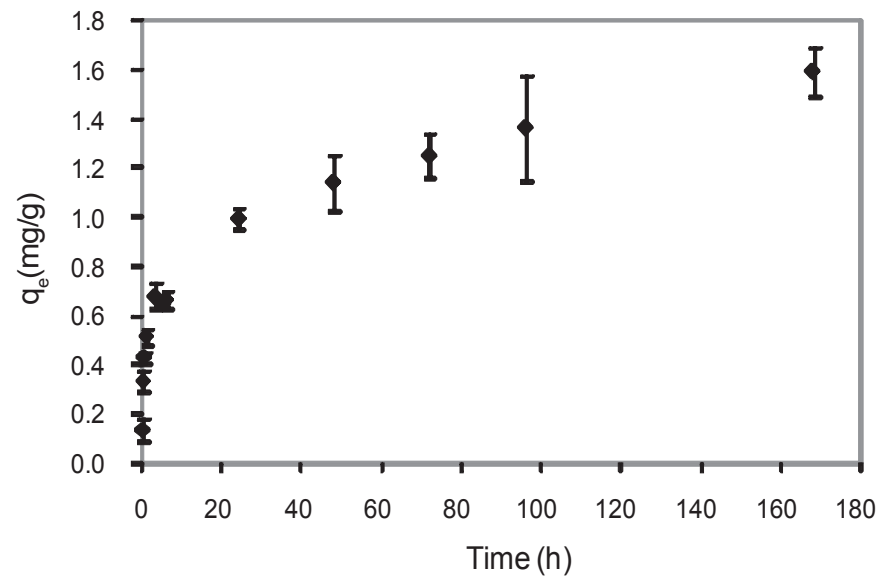

Fig. 5. Sorption kinetics of remazol yellow by Fe-zeolitic tuff. 
this is a disadvantage when adsorption material is employed in waste water treatments.

Several kinetic models were applied to the experimental data of the sorption of remazol yellow by Fe-zeolitic tuff. The feature constants of sorption were obtained by using a pseudo first order model, Elovich model and pseudo second order model. The sorption behavior of the dye was analyzed using linear regression.

\section{Pseudo first order model (Lagergren)}

This model is commonly used for homogeneous sorbents and physical sorption; the sorption rate is proportional to the solute concentration. If the sorption behavior is of the first order, then the experimental results could be adjusted to the following equation:

$$
q_{t}=q_{e}\left(1-e^{-K t}\right)
$$

with the linear form being:

$$
\ln \left(1-\left(q_{t} / q_{e}\right)\right)=-K t
$$

where $q_{t}$ and $q_{e}$ are the amounts of adsorbed dye $(\mathrm{mg} / \mathrm{g})$ in the equilibrium and at time $t(h)$, respectively and $K\left(\mathrm{~h}^{-1}\right)$ is the sorption constant of Lagergren [24]. $K, q_{e}$; their respective correlations are shown in Table 2.

\section{Second order model (Elovich)}

This model has been used suitably in chemisorptions on highly heterogeneous materials [25] and is represented by the following equation:

$$
q_{t}=\beta \ln (\alpha \beta)+\beta \ln (\mathrm{t})
$$

where $q_{t}$ is the amount of adsorbed dye at time $t, \alpha$ is the sorption constant of the dye $(\mathrm{mg} / \mathrm{g})$ and $\beta$ is the desorption constant (mg/g). Thus, the constant can be obtained from the slope and intercept of the linear plot of $q_{t} v s . \ln (t)$. Table 2 shows the kinetic constants obtained with this model.

\section{Pseudo-second order model}

The pseudo second order model, proposed by Ho and McKay [26], is based on the assumption that the rate-limiting step may be chemisorption involving valence forces through the sharing or exchange of electrons between adsorbent and adsorbate. This model can be represented in the following form:

$$
t / q_{t}=\left(1 / k q_{e}^{2}\right)+\left(1 / q_{e}\right) t
$$

where $q_{t}$ and $q_{e}$ are the amount adsorbed at time $t$ and at equilibrium $(\mathrm{mg} / \mathrm{g})$, respectively, and $k$ is the pseudo second order rate constant for the sorption process $(\mathrm{g} / \mathrm{mg} \mathrm{h})$. Thus, a plot of $t / q t v s$. $t$ should give a linear relationship with a slope of $1 / q_{e}$ and an intercept $1 / k q_{e}^{2}$. It was found that the adsorption system was best described by the pseudo-second order model. Figure 6 shows the adjustment of the experimental data to this model, the calculated $k$ and $q_{e}$ parameters being included in Table 2.

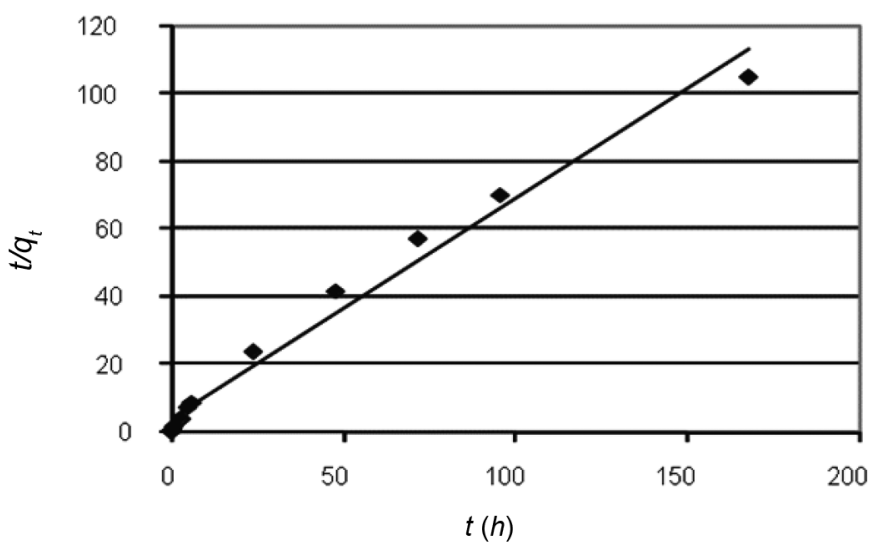

Fig. 6. Kinetic pseudo-second order model applied to the remazol yellow dye sorption from aqueous solution by Fe-zeolitic tuff.

Table 2. Kinetic parameters of remazol yellow by Fe-zeolitic tuff.

\begin{tabular}{cccc}
\hline Kinetic model & Equation & Parameters & $r^{2}$ \\
\hline First order & $q_{t}=1.4\left(1-e^{-0.03 t}\right)$ & $\begin{array}{c}q_{e}=1.4 \mathrm{mg} / \mathrm{g} \\
K=0.3 \mathrm{~h}-1\end{array}$ & 0.96 \\
Elovich & $q_{t}=0.17 \ln (17.71)+0.17 \ln (t)$ & $\begin{array}{c}\alpha=101.21 \mathrm{mg} / \mathrm{g} \\
\beta=0.17 \mathrm{mg} / \mathrm{g} \\
k=0.09 \mathrm{~g} / \mathrm{mg} \mathrm{h} \\
\text { Pseudo second order }\end{array}$ \\
& $\frac{t}{q_{t}}=\frac{1}{(0.09)(1.54)^{2}}+\frac{1}{1.54}$ & 0.95
\end{tabular}




\section{Sorption isotherms}

The maximum sorption capacity of sorbents was obtained from the sorption isotherms to optimize the use of these materials. The experimental results were analyzed by non-linear Langmuir, Freundlich and Langmuir-Freundlich sorption models. The experimental data were analyzed with the help of STATISTICA $^{\circledR}$ version 6.0 software.

\section{Langmuir model}

This model considers that maximum sorption corresponds to a monolayer saturated with dye molecules on the sorbent surface [27]. The Langmuir isotherm is represented by the following equation:

$$
\mathrm{q}_{\mathrm{e}}=\left(\mathrm{q}_{0} \mathrm{~b} \mathrm{C}_{\mathrm{e}}\right) /\left(1+\mathrm{b} \mathrm{C}_{\mathrm{e}}\right)
$$

where $q_{0}$ is the amount of dye adsorbed per unit weight of the adsorbent in forming a complete monolayer on the surface $(\mathrm{mg} / \mathrm{g}), q_{e}$ is amount of dye adsorbed $(\mathrm{mg} / \mathrm{g}), C_{e}$ is the concentration of the dye in the solution at equilibrium $(\mathrm{mg} / \mathrm{L})$ and $b$ is the constant related to the energy or net enthalpy of sorption. Table 3 shows the parameters obtained by applying this model to the experimental results; although the correlation was not perfect, it was still possible to calculate the sorption capacity of the zeolitic material for remazol yellow.

\section{Freundlich model}

The Freundlich model, which has been applied to adsorbents with heterogeneous surfaces, considering multilayer sorption [14], is given by the following formula:

$$
q=K_{f} C_{e}{ }^{1 / n}
$$

where $q$ is the amount of dye adsorbed per unit weight of adsorbent $(\mathrm{mg} / \mathrm{g}), C_{e}$ is the equilibrium concentration of the dye in the solution $(\mathrm{mg} / \mathrm{L}), K_{f}$ is the equilibrium constant indicative of adsorption capacity and $\mathrm{n}$ is the adsorption equilibrium constant whose reciprocal is indicative of the heterogeneity of surface sorbent. $K_{f} ; 1 / \mathrm{n}$ and qe parameters are reported in Table 3. According to the characteristics of the sorbent, it is better to apply this model to the results than the Langmuir model because it is a heterogeneous material.

The values of $1 / \mathrm{n}$ are similar and less than unity, implying a heterogeneous surface structure with minimum interaction between adsorbed atoms [28].

\section{Langmuir-Freundlich model}

The Langmuir-Freundlich model is a combination of Langmuir and Freundlich models [14] and can be represented by the following equation:
Table 3. Sorption isotherm parameters of remazol yellow by Fe-zeo-

\begin{tabular}{|c|c|c|c|}
\hline Model & Equation & Parameters & $r^{2}$ \\
\hline Langmuir & $q_{e}=\frac{(3.49)(0.37) C_{e}}{1+0.37 C_{e}}$ & $\begin{array}{c}q_{o}=3.49 \mathrm{mg} / \mathrm{g} \\
b=0.37\end{array}$ & 0.85 \\
\hline Freundlich & $q=1.08 C_{e}^{1 / 2.30}$ & $\begin{array}{c}K_{f}=1.08 \\
n=2.30\end{array}$ & 0.95 \\
\hline $\begin{array}{l}\text { Langmuir- } \\
\text { Freundlich }\end{array}$ & $q_{e}=\frac{(0.12) C_{e}^{(1 / 23.30)}}{1+(-0.87) C_{e}^{(1 / 23.06)}}$ & $\begin{array}{l}K=0.12 \\
n=23.30 \\
a=-0.87\end{array}$ & 0.98 \\
\hline
\end{tabular}
litic tuff.

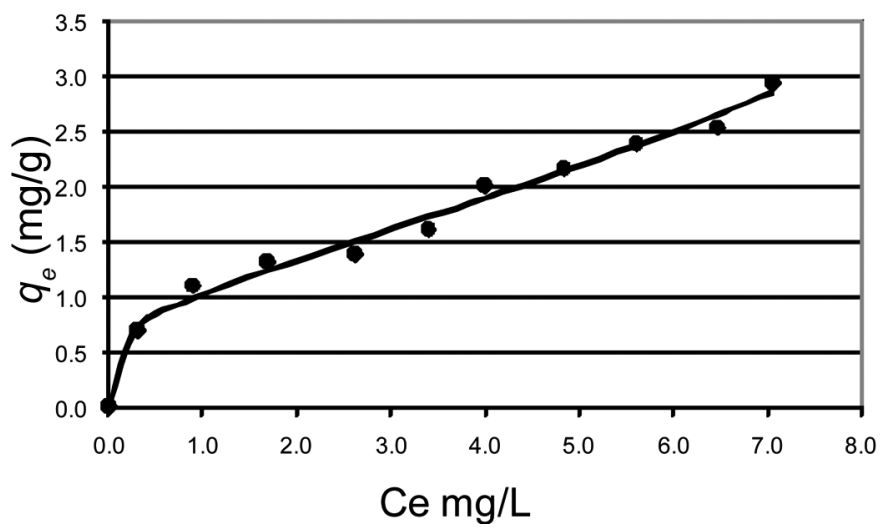

Fig. 7. Langmuir-Freundlich isotherm applied to the remazol yellow dye sorption from aqueous solution by Fe-zeolitic tuff.

$$
q_{e}=\left(K C_{e}^{1 / n}\right) /\left(1+a C^{1 / n}\right)
$$

where $q_{e}$ is the amount of dye adsorbed per unit weight of adsorbent $(\mathrm{mg} / \mathrm{g}), C_{e}$ is the equilibrium concentration of dye in solution, $\mathrm{K}$ and a are empirical constants.

The correlation coefficients were greater than 0.8 for the previous methods; the data correlated best with the LangmuirFreundlich model, which had the highest correlation coefficients, as seen in Table 3 and Figure 7. Similar results were found by Dhaouadi and M'Henni [29] who used crude dehydrated sewage sludge.

Considering that the kinetic results obtained with the Fezeolitic tuff were best fitted to the pseudo-second order model and the isotherms to the Langmuir-Freundlich model, it can be suggested that the sorption mechanism of the dye is chemisorption on a heterogeneous material. The same behavior was reported by Torres-Pérez et al. [30] working with a modified zeolitic material with HDTMA (hexadecyltrimethylammonium) and remazol yellow.

\section{Desorption of remazol yellow}

The desorption results using different solutions are shown in Table 4; as observed, the dye in the modified zeolitic mate- 
Table 4. Desorption of remazol yellow dye from the Fe-zeolitic tuff using different solutions.

\begin{tabular}{lcc}
\hline \multicolumn{1}{c}{ Solution } & $\begin{array}{c}\text { Sorption } \\
\text { Remazol yellow } \\
\text { desorbed (\%) } \\
\text { capity of the } \\
\text { dye saturated } \\
\text { Fe-zeolitic tuff } \\
\text { after being in } \\
\text { contact with the } \\
\text { solutions. }\end{array}$ \\
\hline $\mathrm{H}_{2} \mathrm{O}_{2}$ & 0.0 & 80.81 \\
Fenton's reagent & 54.96 & 92.35 \\
FeCl $_{3}$ & 45.82 & 121.21 \\
Aqueous solution, $\mathrm{pH}=1_{\text {Aqueous solution, } \mathrm{pH}=3}$ & 0.00 & - \\
Aqueous solution, $\mathrm{pH}=6.7$ & 1.05 & - \\
Aqueous solution, $\mathrm{pH}=9$ & 1.29 & - \\
Aqueous solution, $\mathrm{pH}=11$ & 6.27 & 54.33 \\
\hline
\end{tabular}

rial is stable in $\mathrm{pH}$ values from 1 to 9; a similar behaviour was reported by Torres-Pérez et al. [30], who used a surfactant modified zeolite. The desorption of the dyes increases as the $\mathrm{pH}$ of the solutions increases and therefore the materials does not absorb any more dye. The saturated Fe-zeolitic tuff with remazol yellow, treated with an aqueous solution of $\mathrm{pH} 11$ and then left in contact with the remazol yellow solution, showed a sorption capacity of $54.3 \%$.

$\mathrm{H}_{2} \mathrm{O}_{2}$ is one of the oxidation agents most used [31], its degradation producing water and oxygen. After being in contact dye saturated Fe-zeolitic tuff with the $\mathrm{H}_{2} \mathrm{O}_{2}$ solution, remazol yellow was not found in the solution; however, the sorption capacity of the resulting zeolitic material for the dye was $80.8 \%$. This behaviour shows that the dye is decomposed by the $\mathrm{H}_{2} \mathrm{O}_{2}$ solution, and it was therefore not detected in the remaining solutions.

When the saturated zeolitic material was treated with the Fenton's reagent as described above, the desorption percent was about $55 \%$ and the sorption capacity of the resulting zeolitic material was $92 \%$; this behaviour is similar to the one observed by Torres-Pérez et al. [30] with a surfactant modified zeolite. $\mathrm{FeCl}_{3}$ was the best reagent used for the desorption of remazol yellow since the adsorption capacity of the resulting zeolitic material increased $21 \%$ with respect to the original Fe- zeolitic tuff.

\section{Desorption kinetics}

The desorption kinetics of yellow remazol from the dye saturated Fe-zeolitic tuff was determinated with an $\mathrm{H}_{2} \mathrm{O}_{2}$ solution, an aqueous solution of pH 11 and Fenton's reagent solution.

When the dye saturated Fe-zeolitic tuff was treated with $\mathrm{H}_{2} \mathrm{O}_{2}$ solution, the remazol yellow content in the Fe-zeolitic tuff did not change up to 72 hours of contact time. Remazol yelow was determined in the remaining aqueous solutions, this behaviour may be explained in two ways: the first one could indicate that remazol yellow is stable in the zeolitic tuff and is not desorbed; the second could indicate that the dye is decomposed by the $\mathrm{H}_{2} \mathrm{O}_{2}$ solution [32] and therefore was not observed in the remaining aqueous solutions. It is important to note that some bubbles were observed when the dye saturated Fe-zeolitic tuff was put into contact with the $\mathrm{H}_{2} \mathrm{O}_{2}$ solution; this behaviour may indicate the decomposition of the dye. However the dye did not decompose when it was treated only with the $\mathrm{H}_{2} \mathrm{O}_{2}$ solution, suggesting that iron plays an important role in the dye decomposition.

Figure 8 shows the desorption kinetics of yellow remazol from the dye saturated Fe-zeolitic tuff using a $0.02 \mathrm{M} \mathrm{FeCl}$ solution. A fast desorption occurs in the first minutes and then it slows down an almost complete desorption of the dye was observed in about 24 hours. Similar desorption behaviour was observed with an aqueous solution of $\mathrm{pH} \mathrm{11,} \mathrm{but} \mathrm{in} \mathrm{this} \mathrm{last}$ case only about $27 \%$ of the dye was desorbed after 72 hours from the dye saturated Fe-zeolitic tuff.

Table 5 shows the sorption percent of remazol yellow dye with respect to the first sorption process by the Fe-zeolitic material treated with the $\mathrm{H}_{2} \mathrm{O}_{2}$ solution, the aqueous solution of $\mathrm{pH} 11$, Fenton's reagent and the $\mathrm{FeCl}_{3}$ solution for five sorption-desorption cycles. It was found that dye sorption was the highest when the Fe-zeolitic tuff was treated each time with the $\mathrm{H}_{2} \mathrm{O}_{2}$ solution: the sorption capacity increased up to $274.9 \%$ in the fourth cycle, but opposite behaviour was reported with a surfactant modified zeolite [14]. The sorption was the lowest when the samples were treated with an aqueous solution of $\mathrm{pH} \mathrm{11;} \mathrm{the} \mathrm{sorption} \mathrm{capacity} \mathrm{decreased} \mathrm{with} \mathrm{the}$ cycle number, and in the fifth cycle the sorption capacity was only $10 \%$.

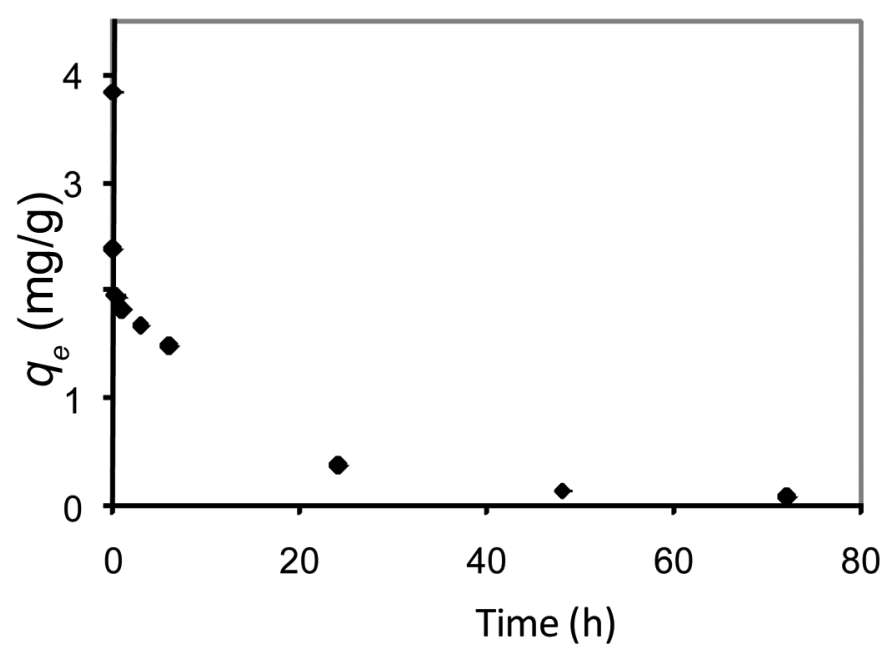

Fig. 8. Desorption kinetics of remazol yellow from dye saturated Fezeolitic tuff using $0.02 \mathrm{M} \mathrm{FeCl}_{3}$ solution. 
Table 5. Sorption percent of remazol yellow by modified zeolitic samples in relation to the first sorption process during five sorption-desorption cycles.

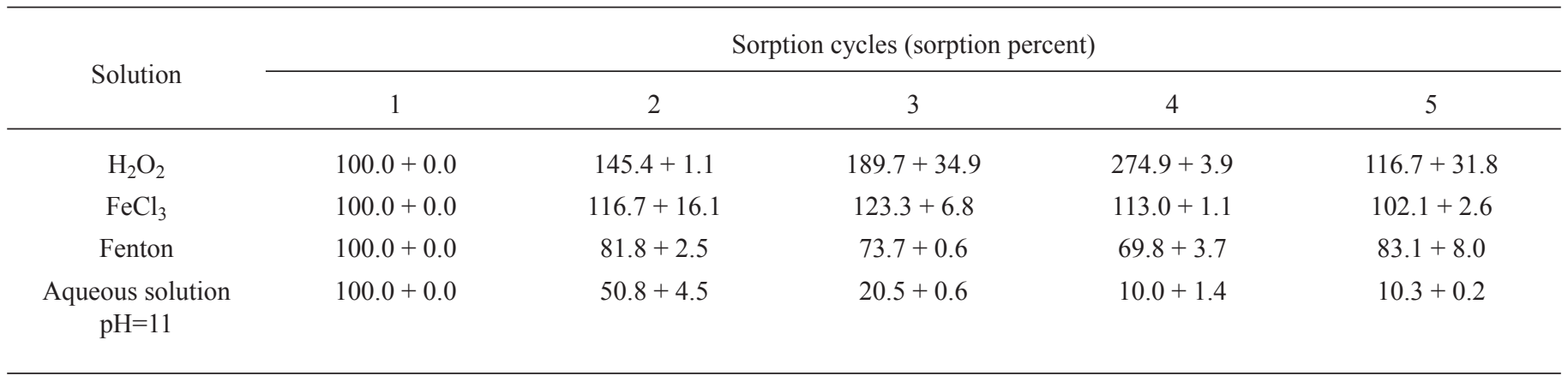

These results show that $\mathrm{Fe}$ (III) and $\mathrm{H}_{2} \mathrm{O}_{2}$ are necessary for the degradation of remazol yellow. According to the results and those reported elsewhere [14], the regeneration of Fe-zeolitic tuff used in the sorption of remazol yellow is easier than the surfactant modified zeolitic tuff; because the former can be regenerated with an $\mathrm{H}_{2} \mathrm{O}_{2}$ solution. Gutiérrez et al. [17] reported that the chemical species of the dye has an important effect on the sorption of indigo carmine on the $\mathrm{Fe}$ zeolitic tuff.

A possible interaction mechanism of the dye with the zeolitic material is catalytic degradation; recently, Kasiri et al. [33] used Fe-ZSM5 zeolite as a heterogeneous photo-Fenton catalyst for the degradation of acid blue 74 .

\section{Conclusions}

Fe-zeolitic tuff is a suitable sorbent for the removal of dyes such as remazol yellow from aqueous solutions. A pseudosecond order model and the Langmuir-Freundlich model were successfully applied to the experimental data obtained with the Fe-zeolitic tuff, which may indicate that the sorption mechanism of the dye on this material is one of chemisorption on a heterogeneous material.

The regeneration of the material was best accomplished by using a $\mathrm{H}_{2} \mathrm{O}_{2}$ solution since the sorption capacity of the Fe-zeolitic tuff for remazol yellow increased when the saturated samples were treated with a $\mathrm{H}_{2} \mathrm{O}_{2}$ or $\mathrm{FeCl}_{3}$ solution.

\section{Experimental}

\section{Materials and Methods}

\section{Fe-zeolitic tuff}

The clinoptilolite-rich tuff from Parral, Chihuahua, Mexico was milled and sieved. The grain size used in this work was between 1.19-1.68 $\mathrm{mm}$. The zeolitic material was treated with a solution of sodium chloride and refluxed (50 $\mathrm{g}$ of material with $250 \mathrm{~mL}$ of $0.125 \mathrm{M} \mathrm{NaCl}$ ). This procedure was repeated 4 times. Afterwards, the zeolitic material was washed with distilled water until no presence of chloride ions was indicated in the washing solution using a $\mathrm{AgNO}_{3}$ test. The sodium-treated zeolitic tuff was then dried at $333 \mathrm{~K}$ for $2 \mathrm{~h}$.

Fe-zeolitic tuff was prepared by mixing $40 \mathrm{~g}$ of the sodium zeolitic tuff with $500 \mathrm{~mL}$ of $0.1 \mathrm{M} \mathrm{FeCl}_{3} \cdot 6 \mathrm{H}_{2} \mathrm{O}$ solution. This procedure was carried out twice in the same way as above. The Fe-zeolitic tuff was then dried at $333 \mathrm{~K}$ for $2 \mathrm{~h}$. The weight of the zeolitic material decreased after each conditioning; this behavior could be due to the removal of fine particles during the conditioning processes.

\section{Characterization}

\section{Scanning electron microscopy}

For scanning electron microscopy (SEM) observations, the Fe-zeolitic tuff samples before and after remazol yellow sorption were mounted directly on the holders and then observed at 10 and $20 \mathrm{kV}$ in a JEOL JSM-5900-LD electron microscope. The microanalysis was done with an EDS (Energy X-ray Dispersive Spectroscopy) system.

\section{Surface Areas, BET $\left(\mathbf{S}_{\mathrm{BET}}\right)$}

The BET specific surface areas were determined by standard multipoint techniques of nitrogen adsorption using a Micromeritics Gemini 2360 instrument. The samples were heated at $373 \mathrm{~K}$ for $2 \mathrm{~h}$ before specific surface areas were measured.

\section{Ray Diffraction (XRD)}

Powder diffractograms of the zeolitic samples were obtained with a Siemens D500 diffractometer coupled to a copper anode X-ray tube. The conventional diffractograms were used to 
identify the compounds and to verify crystalline structure and were compared with clinoptilolite patron (JCPDS 039-1383) and quartz (JCPDS 33-1161).

\section{IR spectroscopy}

The IR spectra in the $4000-400 \mathrm{~cm}^{-1}$ range were recorded for the dye and the adsorbents treated with it at room temperature using a Nicolet Magna IRTM 550 FTIR. Samples were prepared following the standard $\mathrm{KBr}$ pellets method.

\section{Sorption kinetics}

Kinetic removal of remazol yellow dye by the Fe-zeolitic tuff was performed as follows: $100 \mathrm{mg}$ of the adsorbent and $10 \mathrm{~mL}$ aliquots of a $40 \mathrm{mg} / \mathrm{L}$ solution were placed in centrifuge tubes and shaken for different time periods $(5,15$ and $30 \mathrm{~min}, 1,3$, $5,6,24,48,72$ and $168 \mathrm{~h}$ ) at $120 \mathrm{rpm}$ in a shaker at $30{ }^{\circ} \mathrm{C}$. Later, the samples were centrifuged and decanted; the experiments were carried out in duplicate. The remazol yellow dye concentrations in the solutions were determined using a UV/ Vis Perking Elmer Lambda 10 ultraviolet-visible spectrophotometer analyzer, with $\lambda=485.47 \mathrm{~nm}$. The $\mathrm{pH}$ of each solution was measured before and after the treatments.

\section{Sorption isotherms}

One hundred milligrams of samples of the Fe-zeolitic tuff were put into contact with $10 \mathrm{~mL}$ of different concentrations of remazol yellow dye solutions $(10,20,30,40,50,60,70,80$, 90 and $100 \mathrm{mg} / \mathrm{L}$ ) for $168 \mathrm{~h}$ at $30{ }^{\circ} \mathrm{C}$. The experiments were performed in duplicate. Later, the samples were centrifuged and decanted. Dye concentrations were determined in the liquid phases as described above and the $\mathrm{pH}$ was measured in each solution.

\section{Desorption of the remazol yellow from the saturated Fe-zeolitic material.}

Fe- zeolitic material was saturated with remazol yellow as follows: The Fe-zeolitic material was left for $168 \mathrm{~h}$ in contact with a $100 \mathrm{mg} / \mathrm{L}$ solution of remazol yellow, the phases were separated and the concentration of dye in the aqueous phase was measured in order to determine the quantity of dye retained by the Fe-zeolitic material. The saturated zeolitic material was washed with distilled water to eliminate the excess of dye solution; finally the zeolitic material was dried at room temperature.

Samples of the Fe-zeolitic material saturated with remazol yellow $(100 \mathrm{mg}$ ) were left for $24 \mathrm{~h}$ in contact with $10 \mathrm{~mL}$ of the following aqueous solutions: $30 \% \mathrm{H}_{2} \mathrm{O}_{2}, 0.02 \mathrm{M} \mathrm{FeCl}_{3}$, the
Fenton reactive $\left(0.01 \mathrm{M} \mathrm{FeCl}_{3}, 3 \% \mathrm{H}_{2} \mathrm{O}_{2}\right)$, acid solutions pH 1 and 3 , basic solutions $\mathrm{pH} 9$ and 11 . The phases were separated and the concentrations of remazol yellow were measured in the aqueous solutions and desorption percentages were calculated. The zeolitic materials were washed with distilled water, dried and left for $48 \mathrm{~h}$ with $10 \mathrm{~mL}$ of a $100 \mathrm{mg} / \mathrm{L}$ of remazol yellow solution and the regeneration percentages were calculated considering the sorption quantities of dye in the saturation process. This last process was carried out 5 times to determine efficiency of the adsorbent in five sorption-desorption processes.

\section{Desorption kinetics}

Desorption kinetics was carried out with the solutions that showed the highest regeneration of the sorption material, which were a $30 \% \mathrm{H}_{2} \mathrm{O}_{2}$ solution, the Fenton reactive $(0.01 \mathrm{M}$ $\mathrm{FeCl}_{3}, 3 \% \mathrm{H}_{2} \mathrm{O}_{2}$ ) and the solution of $\mathrm{pH} 11$.

$100 \mathrm{mg}$ of the zeolitic material saturated with remazol yellow samples and $10 \mathrm{~mL}$ aliquots of each solution were placed in centrifuge tubes and shaken for different time periods $(5,15$ and 30 minutes, 1, 3, 6, 24, 48 and $72 \mathrm{~h}$ ) at $120 \mathrm{rpm}$ in a shaker at $30{ }^{\circ} \mathrm{C}$. The samples were then centrifuged and decanted; the experiments were performed in duplicate. The remazol yellow dye concentrations in the solutions were determined using a UV/Vis Perking Elmer Lambda 10 ultraviolet-visible spectrophotometer analyzer, with $\lambda=485.47 \mathrm{~nm}$. The $\mathrm{pH}$ of each solution was measured before and after the treatments.

\section{Acknowledgements}

We acknowledge financial support from CONACYT, project 46219-Q.

\section{References}

1. Sanghi, R.; Bhattacharya, B. Color Technol. 2002, 118, 256-269.

2. Lee, J. W.; Choi, S. P.; Thiruvrnkatachari, R.; Shim, W. G.; Moon, H. Dyes Pigments. 2006, 69, 196-203.

3. Allen, S. J.; Koumanova, B. J. Univ. Chem. Technol. Met. 2005, 40, 175-192.

4. Bansal, R. C.; Donnet, J. B; Stoeckli, F., on the pages. 266-269 of the book "Active carbon / Ed. By Roop Chand Bansal, JeanBaptiste Donnet and Fritz Stoeckli, Marcel Dekker, Inc., New York (1988).

5. Huling, S. G.; Jones, P. K.; Ela, W. P.; Arnold, R. G. Water Res. 2005, 39, 2145-2153.

6. Huling, S. G.; Jones, P. K.; Ela, W. P.; Arnold, R. G. J. Environ. Eng.-ASCE 2005, 131, 287-297.

7. Ferro-Garcia, M. A.; Rivera-Utrilla, J.; Bautista-Toledo, I; Moreno-Castilla, C. J. Chem. Technol. Biotechnol. 1996, 67, 183-189.

8. Rivera-Utrilla, J.; Ferro-Garcia, M. A.; Bautista-Toledo, I.; Sanchez-Jimenez, C.; Salvador, F.; Merchan, M. D. Water Res. 2003, 37, 1905-1911.

9. San Miguel, G.; Lambert, S. D.; Graham, N. J. D. Water Res. 2001, 35, 2740-2748. 
10. Lee, S. K.; Chung, M. S.; Oh, W. J.; Park, H. S. Jpn. Kokai Tokkyo Kohk, Jpn. Pat. 1999, 11147708 A2.

11. Clifford, A. L.; Dong, D. F.; Mumby, J. A.; Rogers, D. J. US Pat. 1997, $5702587 \mathrm{~A}$.

12. Haber, F.; Weiss, J. Proc. Royal Soc. A 1934, 147, 332-351.

13. Goldstein, S.; Meyerstein, D. Acc. Chem. Res. 1999, 32, 547550.

14. Torres-Pérez, J.; Solache-Ríos, M.; Colín-Cruz, A. Water, Air, Soil Pollut. 2008, 187, 303-313.

15. Kušiæ, H.; Koprivanac, N.; Selanec, I. Chemosphere 2006, 65, 65-73.

16. Feng, J.; Hu, X.; Yue, P. L. Water Res. 2005, 39, 89-96.

17. Gutiérrez-Segura, E.; Solache-Ríos, M.; Colín-Cruz, A. J. Hazard. Mater. 2009, 170, 1227-1235.

18. Mumpton, F. A.; Orsmy, W. C. Clays Clay Miner. 1976, 24, 1-23.

19. Trgo, M.; Pericì, J. J. Colloid Interface Sci. 2003, 260, 166-175.

20. Doula, M. Chemosphere 2006, 67, 731-740.

21. Díaz Nava, M. C.; Olguín, M. T.; Solache-Ríos, M.; AlarcónHerrera M. T.; Aguilar-Elguezabal, A. J. Incl. Phenom. Macro. Chem. 2005, 51/3-4, 231-240.
22. Breck, D. 1973, Zeolite Molecular Sieves, Wiley Interscience Pub., USA.

23. Wang, X. S.; Wang, J.; Sun, Ch. Adsorpt. Sci. Technol. 2006, 24, 517-530.

24. Ho, Y. S.; Chiu, W. T.; Hsu, C. S.; Huang, C. T. Hydrometallurgy 2004, 73, 55-61.

25. Cortés, R.; Martínez, V.; Solache, M. Sep. Sci. Technol. 2004, 39, 2711-2730.

26. Ho, Y. S.; McKay, G. Adsorp. Sci. Technol. 2002, 20, 797-813.

27. Otero, M.; Rozada, F.; Calvo, L. F.; García, A.I.; Morán, A. Dyes Pigments 2003, 57, 55-65.

28. Abou-Mesalam, M. M. Adsorption 2004, 10, 87-92.

29. Dhaouadi, H.; M'Henni, F. Chem. Eng. J. 2008, 138, 111-119

30. Torres-Pérez, J.; Solache-Rios, M.; Olguin, M. T. Sep. Sci. Technol. 2007, 42, 299-318.

31. Panizza, M.; Ceriosola, G. Water Res. 2001, 35, 3887-3893.

32. Krzemieniewski, M.; Debowski, M.; Dobrzynska, A.; Zielinski, M. Water Environ. Res. 2004, 76, 301-309.

33. Kasiri, M. B.; Aleboyeh, H.; Aleboyeh, A. Appl. Catal. B 2008, $84,9-15$ 
